\title{
Efficacy of Groundnut Oil, Wood Ash, Sand and Some Plants Powders against Callosobruchus chinensis in Cowpea Seeds
}

\author{
Ahmed Gumaa Ahmed Gumaa ${ }^{1}$ and Abdelmanan Elzein Hassan Elamin ${ }^{2}$ \\ 1. Plant Protection Department, Ministry of Agriculture, West Kordofan State, Elfula, P.O. Box 150, Sudan \\ 2. Department of Plant Protection Science, Faculty of Natural Resources and Environmental Studies, University of Kordofan, \\ Elobeid 51111, P.O. Box 160, Sudan
}

\begin{abstract}
This study was conducted under Laboratory of Plant Protection Department, Faculty of Natural Resources and Environmental Studies, University of Kordofan, Elobeid in Sudan, during March-June 2015 to assess the effect of six treatments on germination of cowpea seeds infested by Callosobruchus chinensis Linn., a serious Coleoptera pest which damages cowpea seeds. The agents used were groundnut oil, wood ash, sand, neem leaves powder, Rabal leaves powder and hot pepper powder. In the lab bioassay, the results obtained due to the infestation by $C$. chinensis showed that there were highly significant differences $(P>0.01)$ in the number of holes per 100 cowpea seeds between the different treatments at intervals of one month, and up to the end of the storage period, the numbers of holes per 100 cowpea seeds were 44, 740, 859, 856, 841 and 892 holes in the treatments, respectively. The germination of seeds treated with groundnut oil was $60 \%$, while it was zero for the other treatments. It was concluded that the groundnut oil made creamy coat on the seeds and prevented the development of cowpea beetle infestation. Hence, it can be used by farmers at local levels to protect seeds for cultivation.
\end{abstract}

Key words: Bioassay, Callosobruchus chinensis, groundnut oil, number of holes, germination.

\section{Introduction}

Legumes are considered as an important economical and consumption crops grown in the Sudan in particular. The legume plants are valuable and regarded as sources of organic nitrogen which is essential for plant growth and improvement of soil texture. During periods of storage, the seeds are subjected to damage by various stored product pests, and the losses due to insect pests in developing countries ranged between $25 \%$ and $40 \%$ annually. Many insects species that caused the damage to the stored products are the cowpea beetle Callosobruchus chinensis. It can rapidly reproduce and cause serious reduction in weight and value of stored seeds [1]. The specie belongs to the order Coleoptera, family

Corresponding author: Abdelmanan Elzein Hassan Elamin, assistant professor, research field: entomology.
Bruchidae and it has a number of common names, such as pulse beetle [2]. The unwise use of chemicals leads to natural imbalance as well as destruction of the environment components. Many disadvantages, such as insect resistance to pesticides, residues on food stuff, resurgence of secondary pests and hazards to man and animals, were resulted. Under such circumstances, alternative methods like inert dusts, edible oils and plant products could be easily used by farmers [3]. Botanicals have long been known by many tropical farmers and used for many years traditionally to control stored insect pest, like in Ethiopia particularly farmers used different botanicals to protect their maize grain from insect infestation [4, 5]. The modern strategy of pests control is the use of repellants, plants powders, plants oil and inert materials. Each of these methods may be used alone or mixed with other materials for integrated pest 
management towards safeguarding the environment. Adugna et al. [6] mentioned that in some region of Uganda, Tanzania and Eritrea, admixing fine sand, clay dust or wood ashes with their common stored beans food grains was reported. Koona and Njoya [7] reported that several edible and non edible oils were used for a long time for the protection of stored grains and legumes. Also, neem seed oil showed 100\% control of $C$. chinensis for five months when applied at $10 \mathrm{~mL} / \mathrm{kg}$.

In Sudan, according to El-Kamali et al. [8], two Pulicaria species-P. undulata and P. crispa which known locally as Rabal, are currently to be most commonly used as medicine at rural levels, and Ravandeh et al. [9] further mentioned that $P$. undulata is a medical plant used as an insect repellent. The species of the genus Callosobruchus and Caryedon are very damaging pests of stored food and forest leguminous seeds in Kordofan region [10, 11]. Data on infestation, damage, loss and control under different storage condition are rather meager. No information is, however, available on the field status of these pests, especially on leguminous crops in terms of percentage of pod/seed infestation, quantitative losses and control by farmers. The present study was carried out to evaluate the efficacy of some botanicals, inert materials (wood ash, sand) and edible oil against $C$. chinensis in stored cowpea seeds. The general objective of this study was to provide alternative method for control insect pest especially in stored cowpea seeds, and the specific objectives to evaluate the efficiency of some plant powders (red pepper, neem leaves, Rabal leaves), ground nut oil and inert materials (wood ash and sand) to assess the germination of stored cowpea seeds infested by $C$. chinensis.

\section{Materials and Methods}

\subsection{Study Site}

This study was conducted in North Kordofan State, latitudes $11^{\circ} 15^{\prime}$ and $16^{\circ} 45^{\prime} \mathrm{N}$ and longitudes $27^{\circ} 05^{\prime}$ and $32^{\circ} 15^{\prime} \mathrm{E}$, during March-June 2015. The state is located in Central Sudan in the dry semi-arid region.

\subsection{Laboratory Work}

The investigations were executed under laboratory conditions in Department of Plant Protection, Faculty of Natural Resources and Environmental Studies, University of Kordofan, Elobeid. The work started with collection of the cowpea beetle C. Chinensis L. adults from pulse samples obtained from Elobeid market. Local cowpea variety seeds were used for rearing $C$. chinensis. The cowpea seeds were used after manual cleansing from inorganic and organic matters and shriveled seeds. The broken seed and other food grains were removed. Then seeds were placed in an oven to dry at $60{ }^{\circ} \mathrm{C}$ for $10 \mathrm{~min}$ and stored at room temperature for $7 \mathrm{~d}$ in cloth bags, and then sufficient numbers of $C$. chinensis were added. Cloth bags were periodically checked and fresh cowpea seeds were added to serve more adults when needed as stock.

\subsection{Preparation of Materials}

The $1 \mathrm{~kg}$ of green leaves of neem tree Azadirachta indica were collected from the area around the University of Kordofan, and they were left under shade for $5 \mathrm{~d}$ to dry. Dried leaves were ground with an electrical grinder, and then fine powder was stored in clean cloth bags. Also $1 \mathrm{~kg}$ of red pepper pods Capsicum annuum was put in electrical grinder and the powder was kept in cloth bag. Rabal (P. undulate) leaves were prepared by the same procedure. The $1 \mathrm{~L}$ of ground nut oil (Arachis hypogaea L.) was kept for the experiment. Besides, $1 \mathrm{~kg}$ of wood ash and $1 \mathrm{~kg}$ of sand were also prepared for the experiment as treatments. Experiment procedure was done as the methods described by Mohammed-Ahmed [10, 11]. The treatments used were: (1) $250 \mathrm{~g}$ cowpea seeds + $2.5 \mathrm{~mL}$ groundnut oil; (2) $250 \mathrm{~g}$ cowpea seeds $+35 \mathrm{~g}$ wood ash; (3) $250 \mathrm{~g}$ cowpea seeds $+250 \mathrm{~g}$ sand; (4) $250 \mathrm{~g}$ cow pea seeds $+35 \mathrm{~g}$ neem leaves powder; (5) 
250 g cow pea seeds +35 g Rabal leaves powder; (6) $250 \mathrm{~g}$ cow pea seeds $+35 \mathrm{~g}$ hot pepper powder; (7) $250 \mathrm{~g}$ cowpea seeds as control (untreated).

Seven jars were used for the seven treatments, and then 20 of freshly emerged adults of $C$. chinensis were added to each jar. Each jar was covered with piece of cloth and fixed with rubber band. The jars were kept in the laboratory under room conditions, and then left for four months (March to June, 2015). Observations were carried out each month to calculate number of holes per 100 cowpea seeds. Samples were taken from each treatment and replicated three times. Then, the mean was recorded at the end of the storage period (four months). Also, the germination test was done. A bioassay was conducted under lab condition to investigate the value of the above mentioned control agents on the adult beetle. A complete randomized design (CRD) with four replicates was used.

\subsection{Qualitative Loss}

Qualitative loss was determined by the analysis of physical parameter, such as number of holes per 100 seeds and germination percentage which was done by randomly selecting 100 cowpea seeds from each treatment. The 100 seeds were checked for damage, which was indicated by exit holes. The numbers of holes per 100 seeds were counted and recorded. The examined seeds were returned to its original jar. One hundred seeds were taken randomly from each treatment and its germination was assessed. The seeds were put in Petri dish containing moistened filter paper and arranged in a complete randomized design with four replications. The germinated seeds in each Petri dish were counted and then recorded after $7 \mathrm{~d}$. The germination percentage was calculated according to Ref. [12] as follows:

$$
\text { Viability index }(\%)=(\mathrm{NG} / \mathrm{TG}) \times 100
$$

where, NG is number of seeds germinated and TG is total number of seeds tested in each Petri dish.

\subsection{Statistical Analysis}

The collected data were statistically analyzed using Mstatc software. Analysis of variances for all obtained means was computed. Significant differences among treatments were subjected to Duncan's multiple range test (DMRT) $(P<0.05$ level $)$.

\section{Results}

\subsection{Number of Holes}

The mean number of holes per 100 cowpea seeds in all tested treatments was counted at monthly interval over a period of four months (Table 1 and Fig. 1). The mean number of holes after one month was $3,8.75$, $8.25,8.75,10.75,6.75$ and 3.75 in groundnut oil, wood ash, sand, neem leaf powder, Rabal leaf powder, red pepper powder treatments and control, respectively. The mean number of holes after two months was

Table 1 Mean total number of holes per 100 cowpea seeds treated with groundnut oil, wood ash, sand, neem, Rabal and pepper over four months storage period in March-June 2015.

\begin{tabular}{lllll}
\hline \multirow{2}{*}{ Treatments } & \multicolumn{3}{c}{ Number of holes per 100 seeds of cowpea } \\
\cline { 2 - 5 } & 1 st month & 2nd month & 3rd month & 4 th month \\
\hline Groundnut oil & $3.00^{\mathrm{b}}$ & $3.50^{\mathrm{c}}$ & $4.00^{\mathrm{d}}$ & $44.00^{\mathrm{d}}$ \\
Wood ash & $8.75^{\mathrm{ab}}$ & $121.75^{\mathrm{b}}$ & $250.00^{\mathrm{c}}$ & $740.00^{\mathrm{c}}$ \\
Sand & $8.25^{\mathrm{a}}$ & $114.00^{\mathrm{b}}$ & $265.25^{\mathrm{c}}$ & $858.75^{\mathrm{b}}$ \\
Neem leaves powder & $8.75^{\mathrm{b}}$ & $153.25^{\mathrm{b}}$ & $384.50^{\mathrm{a}}$ & $856.00^{\mathrm{a}}$ \\
Rabal leaves powder & $10.75^{\mathrm{b}}$ & $196.00^{\mathrm{a}}$ & $302.25^{\mathrm{b}}$ & $840.75^{\mathrm{b}}$ \\
Red pepper powder & $6.75^{\mathrm{b}}$ & $129.25^{\mathrm{b}}$ & $341.25^{\mathrm{a}}$ & $852.25^{\mathrm{a}}$ \\
Control & $3.75^{\mathrm{b}}$ & $157.00^{\mathrm{b}}$ & $346.00^{\mathrm{a}}$ & $866.25^{\mathrm{a}}$ \\
\hline SE & 1.07 & 11.52 & 22.81 & 54.58 \\
CV\% & 79.58 & 20.06 & 7.54 & 3.10 \\
\hline
\end{tabular}

Means in a column followed by the same letter are not significantly different $(P<0.05)$ according to Duncan's multiple range test (DMRT). 


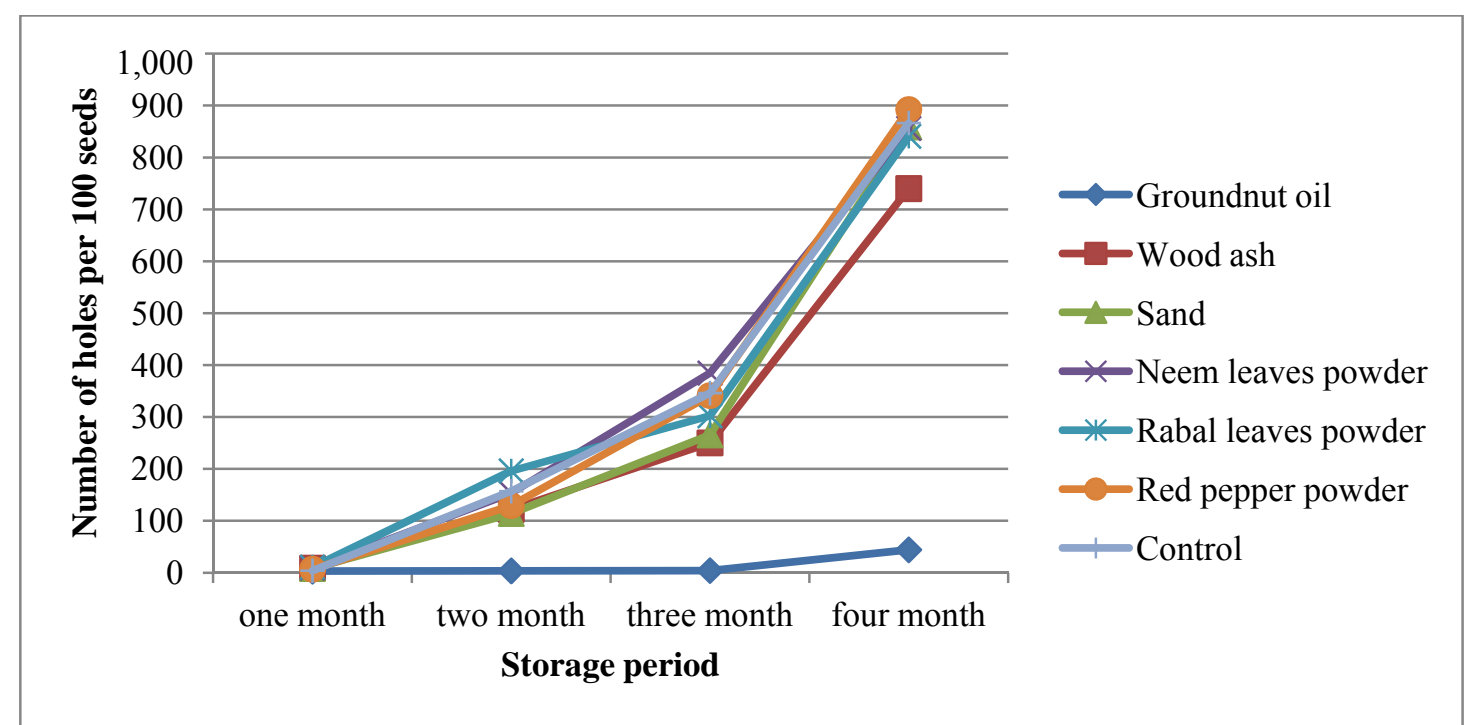

Fig. 1 Mean number of holes per 100 cowpea seeds treated with groundnut oil, wood ash, sand, neem, Rabal and pepper over four months storage period in March-June 2015.

$3.50,121.75,114,153.25,196,129.25$ and 157 , respectively. The mean number of holes after three months was $4,250,265.25,384.50,302.25,341.25$ and 346 in the treatments, respectively. The mean number of holes after four months was 44, 740, $858.75,856,840.75,852.25$ and 866.25 , respectively.

\subsection{Assessment of Germination}

Germination test of cowpea seeds in different treatments was performed at the end of the storage period (four months) for viability of seeds. The germination percentage of cowpea seeds was $60 \%$ for groundnut oil and $0 \%$ for the others. The treatment with ground nut oil gave high germination, while the seeds treated with wood ash, sand, neem leaf powder, Rabal leaf powder and red pepper powder failed to germinate.

\section{Discussion}

In this study, number of holes on 100 seeds of cowpea showed significant difference $(P \geq 0.05)$ between different treatments starting from the first count up to the third one. However, there was highly significant difference $(P=0.01)$ in the subsequent counts, i.e., at the end of the experiment period (four months). The mean total numbers of holes per 100 cowpea seeds infested by $C$. chinensis showed great variation. It was $740,859.75,856,840,852$ in treatment with wood ash, sand, neem, Rabal and pepper, respectively, and for the control, it was 866 holes, while there were only 44 holes per 100 cowpea seeds of the treatment with groundnut oil after the four months when 20 adults were added. The high number of holes showed poor protection and all materials inside the seeds were eaten by the pest; though, the treatment by groundnut oil was the best for protection the cowpea seeds and promising for the control. The germination test showed that groundnut oil gave the best results in percentage germination $(60 \%)$ after four months of storage period, compared with treatment of wood ash, sand, neem, Rabal, pepper and control, which showed no germination. The germination percentage which was classified as loss in quality and nutritive value can result in much more financial loss than what can be accounted for. The weight loss indicated that either the whole embryo or an appreciable portion of it was consumed by $C$. chinensis larvae. This indicated that the beans embryo is very sensitive to infestation by Bruchid, and even a little infestation can cause failure in germination. The results demonstrate the extremely high significance of seed eaten by $C$. chinensis. The seeds, which have 
been attacked by $C$. chinensis, may germinate, if the germ is not damaged or eaten away, but it will die soon or produce weak plants because of non-availability of nutrients during earlier stage of its development. A similar view was also expressed by Krishnamurthy et al. [13]. Also, they reported that some of the varieties of pulse grains are more susceptible to insect infestation than others due to inherited characteristics, like, hardness; the major source of storage infestation is from the field, and cross infestation within stored commodities also occurs. Singh et al. [14, 15] earlier recorded palm and coconut oils at $4 \mathrm{~mL} / \mathrm{kg}$ were the most effective on chick pea seed against $C$. chinensis for three months of storage, followed by groundnut oil, rapeseed and mustard oils, sesame, sunflower and soybean oils. Schmutterer [16] and Bekele et al. [17] mentioned the properties and potential of pesticides from the neem tree, Azadiractha indica and leaves of Ocimum kilimandscharicum (Labiatae) to control stored products pests. In Nepal, Regmi et al. [18] recorded five natural products, including Xanthoylum armatum DC (Rutaceae) fruit powder, Acorus calamus L. (Araceae) rhizome powder, Cinnamom camphora L. (Lauraceae) balls, oil of Sesamum indicum L. (Pedaliaceae), and leaf powder of Azadirachta indica A. Juss. (Meliaceae), can protect the seeds of stored pulse from C. chinensis for up to two generations. The effect of ethanol extract of the leaf from plants Hydrocotyl asiatica, Boerhavia diffusa, Bacopa monieri and Trichosanthes cucumarina was tested against the pulse beetle $C$. chinensi, and the results showed that high doses of the extracts were significantly more toxic to $C$. chinensis compared to lower doses. LD50 value was assessed using probit analysis. The effect of the plant Hydrocotyl asiatica was found to be the most significant, causing the highest mortality compared to other plants [19]. Also, in India, the ethanolic extracts of plant leaves, like Bakain (Melia azedarach), Mint (Mentha longifolia), Habulas (Myrtus communis), Lemongrass
(Cymbopogon citratus) and Datura (Datura stramonium), were tested against the stored grain pests [20]. The efficacy of neem products, like neem oil and commercially available neem formulations, were evaluated in the laboratory for control of pulse beetle $C$. chinensis, and were found effective in stored Bengal gram [21]. Kumawat and Naga [22] concluded that using of oils reduced the losses caused by insects of food products. Further, Fatiha et al. [23] recorded three medicinal plants as protectants against the cowpea weevil, and the test on the seed germination showed no damage to the germinating seed, which agreed with the finding in this study.

\section{Conclusions and Recommendation}

The results of this study showed that cowpea beetle C. chinensis is an important pest on stored cowpea seeds. Qualitative losses were high, even for short storage periods and low population of this pest. Mixing cowpea seeds with groundnut oil is an effective method to protect stored cowpea seed from damage by $C$. chinensis, while wood ash, sand, neem leaf powder, Rabal leaf powder and red pepper powder showed low effect against $C$. chinensis especially for long storage period.

Further studies were needed on other botanical materials, doses and the impact of natural enemies on population dynamics of this pest in Kordofan. Based on the outcomes of this study, it is possible to recommend that the use of groundnut oil is a step to save seeds and avoidance of chemical control is highly recommended in stores. Besides, it is necessary to raise the awareness of the farmers towards Bruchid beetles species and their control. However, more research is needed to explore use of traditional materials that have effects on the stored product pests.

\section{References}

[1] Natural Resource Institute (NRI). 2003. "Manual for Handling and Storage of Food Grains in Tropical and Subtropical Areas of Sitophilus spp. on Stored Sorghum." M.Sc. thesis, Alemaya University, Ethiopia. 
[2] Maheshwari, H. K., Sharma, M. K., and Dwivedi, S. C. 1998. "Effectiveness of Repelin as Surface Protectant against Pulse Beetle Callosobruchus chinensis L. Infesting Cowpea." International Journal of Tropical Agriculture 16: 229-32.

[3] Isman, M. B. 2008. "Botanical Insecticides: For Richer and for Poorer." Pest Management Science 64 (1): 8-11.

[4] Emana, G. 1998. "Use of Botanical Plants in the Control of Stored Maize Grain Insect Pests in Ethiopia." In Proceedings of the Sixth Eastern and South Africa Regional Maize Conference, 105-8.

[5] Selase, A. G., and Getu, E. 2009. "Evaluation of Botanical Plant Powders against Zabrotes subfasciatus (Boheman) (Coleoptera: Bruchidae) in Stored Haricot Beans under Laboratory Condition.” African J. Agri. Res. 4 (10): 1073-9.

[6] Adugna, H., Dangnew, G., Biniam, Z., and Biniam, A. 2003. On-Farm Storages Studies in Eritrea. Dryland Coordination Group (DCG) Report No. 28.

[7] Koona, P., and Njoya, J. 2004. "Effectiveness of Soybean Oil and Powder from Leaves of Lantana camara Linn. (Verbenaceae) as Protectants of Stored Maize against Infestation by Sitophilus zeamais Motsch. (Coleoptera: Curculionidae)." Pak. J. Biol. Sci. 7 (12): 2125-9.

[8] El-Kamali, H. H., Habeballa, R., Abdalla, I., Mohamed, A., Y., Abdelkarim, D., Abass, I. M., and Ali, S. M. 2010. "Genetic Relationships of Two Pulicaria Species and Identification of Their Putative Hybrids Using Rapd Markers.” World Applied Sciences Journal 8 (6): 687-93.

[9] Ravandeh, M., Valizadeh, J., Noroozifar, M., and Khoasani-Motlagh, M. 2011. "Screening of Chemical Composition of Essential Oil Mineral Elements and Antioxidant Activity in Pulicaria undulate (L.) C.A. Mey from Iran.” Journal of Medicinal Plants Research 5 (10): 2035-40.

[10] Mohammed-Ahmed, M. A. 2004. "Biology and Loss in Cowpea Seeds due to Callosobruchus chinensis L. and the Use of Some Plant Material as Protect Ants.” M.Sc. thesis, Faculty of Natural Resources and Environmental Studies, University of Kordofan.

[11] Mohammed-Ahmed, M. A. 2012. "Variation and Host Association among Some Bruchids (Coleoptera) in Kordofan Region, Sudan." Ph.D. thesis, Faculty Agricultural Sciences, University of Gezira, Wad Medani, Sudan .

[12] Ogendo, J. O., Deng, A. L., Belmain, S. R., Walker, D. J., and Musandu, A. A. O. 2004. "Effect of Insecticidal Plant Materials, Lantana camara L. and Tephrosia vogelii Hook, on the Quality Parameters of Stored Maize Grains." J. Food Technol. Afr. 9 (1): 29-36.
[13] Krishnamurthy, K., Medani, H. H., and Mohammed, M. E. 1989. Manual on Storage of Food Grains. FAO Project on Improvement of Storage and Pest Management Procedures for Food Security GCP/SUD/035/AUL, PPD, Wad Medani, Sudan.

[14] Singh, S. R., Singal, S. K., and Verma, A. N. 1990. "Evaluation of Some Edible Oils as Protectants of Chickpea Seeds, Cicer arierinum L. against Pulse Beetle, Callosobruchus chinensis L. by Preferential Feeding Method." In Proceedings of the 5th International Working Conference on Stored-Product Protection, 1715-24.

[15] Singh, S. R., Luse, R. A., Leuschrer, K., and Nangju, D. 1978. "Groundnut Oil Treatment for the Control of Callosobruchus maculatus during Cowpea Storage." J. Stored Prod. Res. 14 (2-3): 77-80.

[16] Schmutterer, H. 1990. "Properties and Potential of Pesticides from the Neem Tree, Azadirachta indica." Annual Review of Entomology 35: 271-97.

[17] Bekele, A. J., Oforiand, D. O., and Hassanali, A. 1995. "Products Derived from the Leaves of Ocimum kilimandscharicum (Labiatae) as Post-Harvest Grain Protectants against the Infestation of Three Major Stored Product Insect Pests.” Bull. Entomol. Res. 85 (3): 361-7.

[18] Regmi, H., Kaflel, L., Gc, Y. D., and Shih, C. J. 2012. "Efficacy of Natural Product against Callosobruchus chinensis (Coleoptera: Bruchidae) in Nepal." J. Econ. Entomol. 105 (3): 1095-9.

[19] Bindhu, V. R., Ganga, S., and Dayanandan, S. 2015. "Mortality Effects of Some Medicinal Plants on the Pulse Beetle Callosobruchus chinensis (Coleoptera: Bruchidae)." J. Biofertil. Biopestici. 6: 150.

[20] Manzoor, F., Nasim, G., Saif, S., and Malik, S. A. 2011. "Effect of Ethanolic Plant Extracts on Three Storage Grain Pests of Economic Importance.” Pak. J. Bot. 43 (6): 2941-6.

[21] Rajasri, M., and Rao, P. S. 2012. "Neem Formulations-Safer Seed Protectants against Pulse Beetle, Callosobruchus chinensis for Long Term Storage of Bengalgram." International Journal of Applied Biology and Pharmaceutical Technology 3 (3): 323-8.

[22] Kumawat, K. C., and Naga, B. L. 2013. "Effect of Plant Oils on the Infestation of Rhyzopertha dominica (Fab.) in Wheat Triticum aestivcum L..” J. Plant Pro. Res. 53 (3): 302-3.

[23] Fatiha, R. A., Kada, R., Khelil, M. A., and Pujade-Villar, J. 2014. "Biological Control against the Cowpea Weevil (Callosobruchus chinensis L., Coleoptera: Bruchidae) Using Essential Oils of Some Medicinal Plants.” J. Plant Pro. Res. 54 (3): 212-7. 